\title{
Working
}

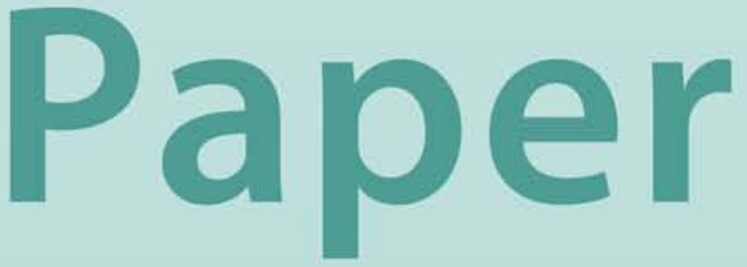




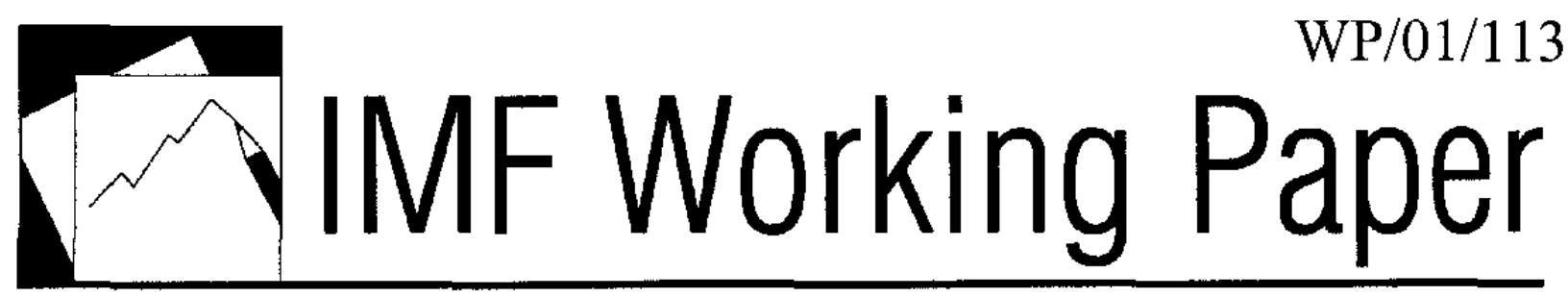

The New Basel Capital Accord: The Devil Is in the (Calibration) Details

\author{
Paul H. Kupiec
}




\title{
IMF Working Paper
}

Monetary and Exchange Affairs Department

\section{The New Basel Capital Accord: The Devil Is in the (Calibration) Details}

Prepared by Paul H. Kupiec

Authorized for distribution by David Marston

August 2001

\begin{abstract}
The views expressed in this Working Paper are those of the author(s) and do not necessarily represent those of the IMF or IMF policy. Working Papers describe research in progress by the author(s) and are published to elicit comments and to further debate.
\end{abstract}

This paper considers characteristics of the capital requirements proposed in The New Basel Capital Accord (2001). Formal analysis identifies calibration features that could give rise to unintended consequences that may include: concentration of credit risk in institutions that are less well equipped to measure and manage risks; an overabundance of thinly capitalized high quality long-maturity credits in foundation Internal Ratings-Based (IRB) banks; distortions in the secondary market for discount or premium credits; an increase in the difficulty of resolving distressed financial institutions; and incentives to distort the accuracy of loan loss provisions.

JEL Classification Numbers:G18, G21, G28

Keywords: bank regulation, Basel Accord, regulatory capital requirements, and credit risk.

Author’s E-Mail Address:pkupiec@imf.org 


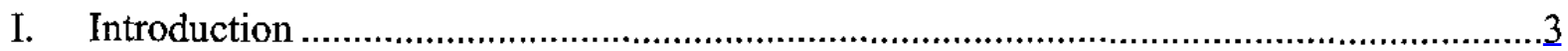

II. Capital Under the Standardized and the Foundation IRB Approaches ............................

III. The Level of Capital Requirements Under the Proposed IRB ...................................

IV. Hold-to-Maturity versus Mark-to-Market Capital? .............................................

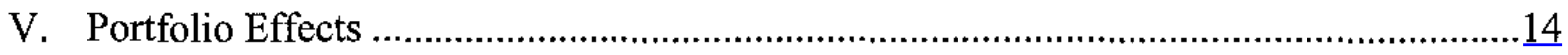

VI. Maturity Corrections and the IRB Approach …...............................................

VII. Par Value and the Foundation IRB Approach ........................................................17

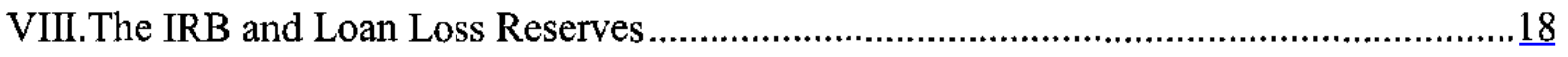

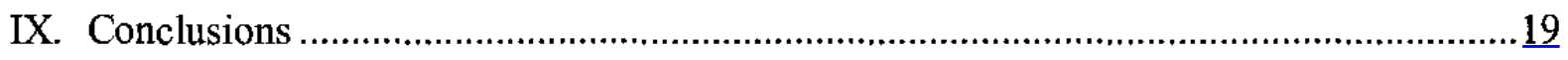

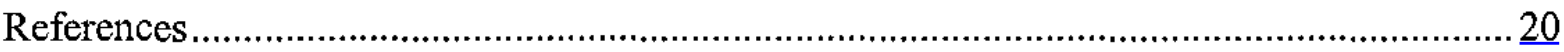

Text Tables

1. Capital Requirements Under the New Basel Accord.................................................

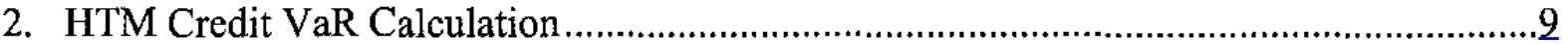

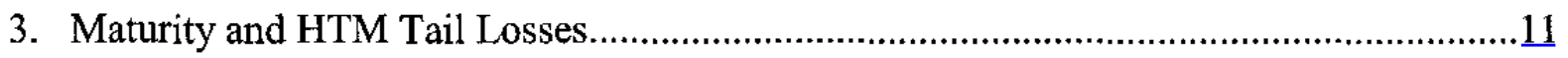

4. Hypothetical Bond Yield Curves (In percent) ........................................................11

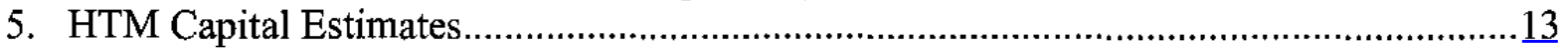

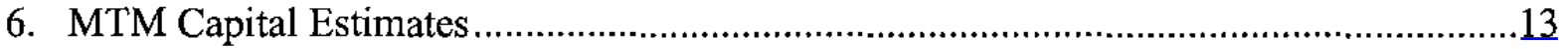

7. Standard Deviation Estimates for Portfolio Value-at-Risk Distributions.........................16

Figure

1. One-Year MTM Capital Requirement by Maturity …...............................................17 


\section{INTRODUCTION}

In January 2001, the Basel Committee on Banking Supervision (the Committee) proposed sweeping revisions (The New Basel Capital Accord) to the 1988 Accord (the Accord). While many aspects of the "three pillars" approach were anticipated in the Committee's June 1999 Consultative Paper, ${ }^{1}$ the January documents are the first to publicly disclose the details of the proposed Internal Ratings Based (IRB) approaches and the proposed capital charges for operational risk.

The primary shortcoming of the 1988 Accord is its inability to adequately differentiate capital requirements according to credit risk. The Accord aggregates counterparties with widely different credit standings into a small number of risk-weight categories. This simplicity makes it relatively easy to "arbitrage" the Supervisors' intended capital constraint through the use of securitization or off-balance sheet exposures, by concentrating bank credit risk exposure in the category with the least credit worthy, highest expected return credits in a risk weight class.

The new Accord offers three alternative approaches for calculating credit risk capital requirements: a new "standardized" approach, and two IRB approaches the so-called "foundation" and "advanced" IRB methods. Relative to the 1988 Accord, all three approaches are more sensitive to the credit risk of an exposure. While this increased sensitivity has been widely applauded in the industry (e.g., see Cass, Crabbe, and Schenke, 2001), this increased sensitivity creates a new set of issues that are not anticipated in the proposal. Unless the new Accord is calibrated correctly, it may engender unintended consequences.

Even considering the hundreds of pages and thousands of person-hours behind the new Accord, significant calibration issues remain. The analysis in this technical note will identify the importance of some of these issues and discuss behaviors that may be encouraged by the proposed calibrations.

\section{CAPITAL Under THe STANDARDIZed AND the Foundation IRB APPROACHES}

The standardized approach for credit risk in the new Accord is a modified version of the 1988 Accord. The new approach expands the scale of risk-weights and uses external credit ratings to categorize credits. As an alternative to the standardized approach, the Committee offers two IRB approaches in which a bank may use its approved internal credit rating model to categorize exposures into multiple credit rating "buckets" of its internal rating system. In the foundation IRB approach, the probability of default associated with each internal bucket and the credit type (corporate, retail, or other category) determine an exposure's risk weight. In the advanced IRB approach, the risk weight is also affected by a bank's estimate of a bucket's loss given default (LGD) and the exposure's maturity.

${ }^{1}$ Bank for International Settlements (1999b). 
The Committee has proposed three alternative credit risk schemes in part because, at present, relatively few banks actually qualify for the IRB approaches. The Committee prefers that banks migrate to the IRB approaches over time, and to encourage migration, the Committee has created an incentive in the form of a lower credit risk capital requirement under the IRB approaches. ${ }^{2}$ This benefit will in part be mitigated by a newly proposed operating risk capital requirement (itself the subject of considerable industry debate). It is instructive to compare capital requirements under these approaches and consider the potential consequences these built-in incentives may create.

Table 1 calculates the credit risk capital charges that apply for a corporate exposure with a Standard and Poor's external credit rating under both the standardized and the foundation IRB approaches. The IRB capital requirements are calculated using the supervisor's proposed BRW $\mathrm{C}_{\mathrm{C}}$ function with one-year average historical default probabilities for each Standard and Poor's rating category. The results in Table 1 show that, for exposures rated $\mathrm{BBB}$ and above, the IRB approach provides a lower capital requirement and thus creates an incentive for banks to adopt it. The results also show that for credits rated below BBB, there is a clear incentive to use the standardized approach as the capital charges under the IRB approach are punitive. Capital charges for credits rated $\mathrm{BB}$ exceed 8 percent, and those for credits $\mathrm{B}$ and below are more than twice the 12 percent capital requirement that applies under the standard approach.

Table 1. Capital Requirements Under the New Basel Accord

\begin{tabular}{|c|c|c|c|c|c|}
\hline S\&P rating & $\begin{array}{r}\text { One-Year } \\
\text { Historical } \\
\text { Default } \\
\text { Probability } \\
\text { Percent } \\
\end{array}$ & $\begin{array}{r}\text { Standardized } \\
\text { Approach } \\
\text { Risk Weight } \\
\text { Percent } \\
\end{array}$ & $\begin{array}{r}\text { Standardized } \\
\text { Approach } \\
\text { Capital } \\
\text { Charge } \\
\text { (per } 100 \text { of } \\
\text { asset value) }\end{array}$ & $\begin{array}{r}\text { BRWc } \\
\text { Risk Weight } \\
\text { (In percent) }\end{array}$ & $\begin{array}{r}\text { Foundation } \\
\text { IRB } \\
\text { Capital } \\
\text { Charge per } \\
100 \text { of Asset } \\
\text { Value }\end{array}$ \\
\hline AAA & .01 & 20 & 2 & 14 & 1.12 \\
\hline $\mathrm{AA}$ & .01 & 20 & 2 & 14 & 1.12 \\
\hline A & .04 & 50 & 4 & 17 & 1.34 \\
\hline BBB & .22 & 100 & 8 & 48 & 3.83 \\
\hline BB & .98 & 100 & 8 & 123 & 9.87 \\
\hline B & 5.30 & 150 & 12 & 342 & 27.40 \\
\hline $\mathrm{CCC}$ & 21.94 & 150 & 12 & 694 & 55.55 \\
\hline
\end{tabular}

Source: Standardized and foundation IRB approach capital charges for Standard and Poor's ratings categorics. The IRB approach charges are calculated using historical one-year default probabilities taken from Standard and Poor's (2001), p. 8, Table 2.

${ }^{2}$ The chairman of the Basel committee reiterated the intention of creating such an incentive in his comments at a discussion of The Capital Accord at the IMF and World Bank, March 22, 2001. 
While the Committee sees these alternatives as fostering incentives to adopt the IRB approach, this dual approach will create a strong clientele effect in which so-called sophisticated banks will specialize in highly rated credits and shun lower quality credits because of the regulatory capital consequences. At the same time, these capital requirements create incentives for "less sophisticated" banks which use the standardized approach to specialize in the lower quality credits.

Unlike the current system of capital requirements that encourages sophisticated banks to securitize high quality credits and retain exposures to lower rated counterparties, the proposed system creates incentives for these same banks to concentrate their exposure to high quality credits. If competition among the most sophisticated banks lowers the returns on high quality credits, given the costs of investing in the development and certification of an IRB technology, and the increased capital applied to lower quality credits under an IRB approach, there will no longer be any incentive for less sophisticated banks to migrate to an IRB approach. The new equilibrium includes a stable clientele in which the least sophisticated banks retain significant exposure concentrations to lower quality credits.

The current relative calibrations of the standardized and foundation IRB approaches do not generate incentives that are consistent with the Committee's objectives. While the dual approach is not inherently a flawed idea, as currently calibrated, the incentive to concentrate credit risks in the least sophisticated banks may not foster a more stable international banking system.

\section{The LeVel of Capital Requirements Under the Proposed IRB}

A separate calibration issue relates to the magnitude of capital requirements for high-quality credits under the proposed IRB approach. The secondary market for corporate bonds primarily is an over-the-counter market in which dealers offer one-sided quotes upon request. ${ }^{3}$ Unlike equities markets, there is not a deep and continuous two-sided (bid-asked) market. For example, acquiring a firm quote on an illiquid bond reportedly can take up to a day. ${ }^{4}$ Given the nature of the market, it is interesting to note that the IRB proposed capital charges for high-grade corporates are likely close to, or perhaps even below, the bid-asked spread transactions cost of trading such bonds. While there are no known data published on the transactions costs of trading corporate bonds, extrapolations from the costs of trading illiquid stocks, or a causal survey of the corporate bond pages on e-brokerage account web pages suggest that when two-way bond quotes exit, the bid-asked spread on high-grade corporates on average exceeds 1 percent of a bond's value; and spreads increase substantially for lower credit quality issues.

\footnotetext{
${ }^{3}$ Saunders, Srinivasan, and Walter (1998), provide limited evidence on the market microstructure of the corporate bond market.

${ }^{4}$ Saunders, Srinivasan, and Walter (1998), p. 7.
} 
Why is the bid-asked spread relevant for bank capital requirements? At a minimum, the bidasked spread is the return a competitive dealer charges for the risk capital required to keep a bond in inventory. If a bond dealer actually holds inventory, the inventory's value is subject to the same risks faced by a bank, only over a much shorter expected holding period. If the required return on the dealer's risk capital is 1 percent, then the amount of economic risk capital supporting the dealer's inventory must be far larger than the capital recommended by the IRB approach. Alternatively, if the dealer is a broker, the bid-asked spread is the competitive cost of finding a bond purchaser or seller. Such costs would be faced by any investor that does not hold a bond to maturity-including a bank. A more direct comparison might be to compare capital requirements to the "haircuts" used by market participants for re-purchase transactions on corporate bonds. Haircuts act like margin requirements in exchange-traded futures and stock transactions. They protect the lender from adverse moves in collateral value. While data on the size of repurchase haircuts for corporate bonds is unavailable, informal surveys of personal contracts at buy-side investment firms suggest that they exceed 1.5 percent.

While some may argue that the IRB capital reductions are necessary to encourage banks to retain high quality credits, it should be noted that it is the relative magnitude, not the absolute magnitude of capital requirements that will influence what types of credits banks will ultimately decide to retain. The existing regulatory arbitrage incentives could be mitigated by raising the capital requirements on lower quality credits, without drastically reducing the capital requirements on high grade credit. Banker's often heard claims that, under the current rules, banks "cannot afford" to own high grade corporate credits is more accurately stated as "they choose not to own" such credits. The existence of bond mutual funds, for example, demonstrates that the risk-return tradeoffs on high-grade corporate credits are perfectly acceptable to investors even under a 100 percent equity capital requirement.

Given safety net related advantages enjoyed by bank debt, the optimal use of bank leverage clearly is the key to optimizing bank equity returns and the reason why banks prefer not to own high quality credits under the current system. If expected return is an increasing function of credit risk exposure, and a banks funding costs are, within limits, insensitive to its credit risk exposures because of public safety net provisions, then a bank maximizes its expected return to shareholders by leveraging lower quality credits. Other things equal, after investing their capital in low quality credits, banks may choose not to raise additional equity capital and leverage higher quality credits because additional equity will dilute shareholder expected returns that are in part derived from the safety net financing subsidy.

Under the current regulatory system, high- and low-quality corporate credits require the same regulatory capital, and thus bank share values are maximized by leveraging lower quality credits with their existing capital. Under a different set of capital requirements in which lower quality credits require higher capital, it could be optimal for banks to own higher quality credits even if the associated capital requirements were not reduced from current levels. The result is that it is entirely possible that the "cure" for the current regulatory arbitrage may be higher capital for lower quality credits, and not the proposed IRB calibration that allows for substantially lower capital for highly rated counterparties. 


\section{Hold-to-Maturity versus Mark-to-Market Capital?}

One difficulty related to the calibrations of the standardized and IRB approaches is a fundamental difference of philosophy associated with the assignment of credit ratings. External credit ratings are based on assessments of a creditor's long-term ability to repay obligations, while the IRB approach has been calibrated using one-year mark-to-market (MTM) credit exposure estimates. ${ }^{5}$

This difference in ratings calibration is related to, yet more profound than, the so-called "procyclicality" debate concerning whether the IRB approach should be calibrated to a long-run (full credit cycle) default probability. The foundation IRB approach measures credit risk according to the probability of default at the end of a single year. In the context of the IRB approach, the procyclicality debate is then just a question of whether it is most appropriate to use a conditional or an unconditional estimate of the one-year probability of default. In contrast to the IRB approach, an external credit rating measures a creditor's ability to honor the entire stream of payments on a long-term bond. In essence, the IRB and standardized approaches measure credit risk over different investment horizons. This is equivalent to using different assumptions about the investment strategy of a bank.

While it has long been recognized that investment strategy can have important implications for risk and expected return, the importance of investment strategy has not been formally recognized in many discussions of capital requirements. A return distribution on a long position in equity differs from the return distribution of a long position in equity protected by a stop-loss order. A bond investor who holds a bond to maturity faces a different potential return distribution than an investor who must liquidate a bond should it fall below investment grade. If investment strategy has a significant influence on the potential return distribution, then under Value-at-Risk (VaR) type measures of risk capital, the strategy will also effect the investment's estimated capital needs.

The credit risk capital requirements in the 1988 Accord were designed to apply to banking book assets. Unless these assets are impaired or nonperforming, they are carried throughout their life on a bank balance sheet at their initial value. These assets, primarily loans, are traditionally held to maturity by a bank. It is commonly believed that, in making loans and holding them to maturity, banks perform a special intermediation function that is critical for capital formation

${ }^{5}$ The MTM label is not completely accurate. If the foundation IRB approach were calibrated using, for instance, CreditMetrics, it would not be a true MTM model since CreditMetrics assumes static credit spreads. With this caveat, we continue to refer to the IRB approach as an MTM one. 
and economic growth. Conventional wisdom holds that, for the most part, loans are not marketable and it is difficult, if not impossible, to accurately mark them to market. The inability to market loans and the importance of the intermediation function performed by banks is formally recognized by banks as privileged access to central bank lender-of-last-resort facilities where solvent banks can, if need be, liquefy their non-marketable loan portfolios.

The newly proposed standardized approach is a modified version of the 1988 Accord and implicitly takes a held-to-maturity (HTM) view of the banking book. This view is reinforced by the proposed use of external credit ratings which inherently are an HTM measure of credit risk.

In contrast to the standardized approach, the IRB approaches are derived from one-year MTM credit VaR models. A one-year MTM approach to capital is consistent with a one-year holding period investment strategy: buy a credit and sell it after one-year, regardless. Even under this interpretation, the IRB approaches would undercapitalize positions because its capital calculations ignore the variability of corporate bond spreads which are perhaps the largest source of MTM risk exposure on a high-grade credit portfolio over a short horizon. The risk and return distribution associated with a one-year holding period differs markedly from the distribution associated with a HTM strategy. While it has not widely been recognized in the credit risk measurement literature, a credit VaR style capital requirement may differ markedly across these alternative investment strategies.

If credit risk capital requirements apply primarily to HTM positions, it is important to ask whether or not such positions are appropriately capitalized using one-year MTM credit exposure measures. Such a statement may draw protest from those that hold that the purpose of the new Accord is to move regulatory capital requirements closer to so-called "economic capital" requirements set internally by banks. Such arguments fail to appreciate that "economic capital" enters into many different management processes within a bank, and the ideal measure of "economic capital" depends on the management process being addressed.

Economic capital is used inter alia to set so-called annual risk budgets, to measure the attractiveness of investment alternatives in Risk Adjusted Return on Capital (RAROC) measures, and to determine annual compensation by charging business units for use of the firm's risk capital. While it has not been widely recognized, it can be shown that the optimal measure of "risk capital" is substantially different depending on its intended use. ${ }^{6}$ In general, measures of risk capital that are optimal for use in RAROC measures, risk budgets, and short horizon performance review will not be the same measure that is most appropriately used to ensure a minimum solvency standard under a HTM investment strategy. Given that banking book assets are HTM by definition, it is reasonable to investigate the characteristics of credit risk capital requirements under an HTM strategy.

\footnotetext{
${ }^{6}$ For further discussion, see Kupiec (2001).
} 


\section{A. Simplified HTM VaR}

While there are potentially many ways to define an HTM credit VaR capital estimate, for purposes of exposition, we propose a straightforward generalization of the MTM approach and calculate a credit VaR using the distribution of the present value of potential cash flows under the HTM strategy. Such a generalization would recommend setting credit risk capital equal to the unexpected credit loss in present value terms. ${ }^{7}$ A stylized example of this credit VaR calculation for a five-year Moody's Baa-rated corporate bond selling at par appears in Table 2.

Table 2. HTM Credit VaR Calculation

\begin{tabular}{lrrrrr}
\hline & $\begin{array}{r}\text { Present } \\
\text { Value of } \\
\text { Cash } \\
\text { Event }\end{array}$ & $\begin{array}{r}\text { Cumulative } \\
\text { (In percent) }\end{array}$ & $\begin{array}{r}\text { Flows } \\
\text { Prestibution of }\end{array}$ & $\begin{array}{r}\text { Cumulative } \\
\text { Probability } \\
\text { (In Percent) }\end{array}$ & $\begin{array}{r}\text { Cumulative } \\
\text { Distribution of } \\
\text { Lost Present } \\
\text { Value }\end{array}$ \\
\hline No default & 98.19 & 100.75 & 50.09 & .14 & 49.91 \\
Default year 1 & .14 & 50.09 & 54.22 & .44 & 45.78 \\
Default year 2 & .30 & 54.22 & 58.02 & .83 & 41.98 \\
Default year 3 & .39 & 58.02 & 65.53 & 1.34 & 38.47 \\
Default year 4 & .51 & 61.53 & 64.75 & 1.81 & 35.25 \\
Default year 5 & .47 & 64.75 & 100.75 & 100 & -.75 \\
\hline
\end{tabular}

Source: Held-to-maturity credit VaR calculations for a hypothetical five-year par value corporate bond with a coupon rate of 8.8 percent, an expected yield to maturity of 8.61 percent, and a Moody's credit rating of Baa. Default probabilities are based upon Moody's average default rates 1970-2000.

In this example, the bond's Yield to Maturity (YTM) is 8.8 percent; its Expected Yield to Maturity (EYTM) estimated using Moody's average default rates and a 50 percent recovery rate assumption is 8.61 percent. $^{8}$ The EYTM is used to calculate the present value of cash flows for each of the alternative events that may terminate the HTM investment. Because the cash flows in the loss distribution estimates are present values and the bond is purchased at fair market value, the expected loss in the credit VaR calculation is 0 . The 1 percent credit VaR capital estimate lies between 41.98 ( 0.83 percent) and 38.47 (1.34 percent) in this example. A richer cumulative loss distribution could be generated using a finer default timing grid or by using interpolation to generate an approximate distribution function for the tail loss region.

${ }^{7}$ Similar to an MTM credit VaR calculation, this straight--forward generalization in terms of the present value loss function will not produce accurate default rate estimates because it ignores the characteristics of the funding debt. For further discussion, see Kupiec (2001) forthcoming.

${ }^{8}$ The EYTM is the YTM calculated using expected bond cash flows in place of the promised bond cash flows. The expected cash flows are estimated using estimated default probabilities and a 50 percent recovery rate assumption applied to par plus accrued interest. 
In this HTM credit VaR calculation, it is interesting to note that, if the bond is purchased at par, the earlier it defaults, the larger is the loss in present value terms. The longer the time before a default event, the larger is the present value of the interest payments received. Moreover, for a given Moody's rating, the projected probabilities of default are independent of the credit's maturity: the probabilities of default at the end of years one through five are identical for a five-year and a twenty-year bond. An implication is, provided that the slope of the yield curve for a single rating is not too steep, the extreme tail loss region of the cumulative loss distributions for par bonds are virtually identical for all maturities of a given rating. This correspondence implies that, unlike MTM models, credit VaR HTM capital for par bonds is insensitive to a bond's maturity.

To make this point more concrete, assume that the term structure of credit spreads is flat and all Baa bonds have an 8.8 percent YTM. The HTM credit VaR calculations of Table 2 are repeated for the tails of the ten-year and twenty-year Baa bond value distribution and are reported in Table 3. Notice that the extreme loss event probabilities are identical across these bonds, and the loss given the specific default events are nearly identical. ${ }^{9}$ These differences in the loss estimates are inconsequential for purposes of calculating capital requirements. These loss estimates will remain close in value even if the term structure is not flat, but will change markedly if any of the bonds are purchased at a discount or premium.

\section{B. MTM versus HTM Capital Requirements}

To appreciate the differences that may arise between MTM and HTM credit VaR capital allocations, consider a simplified example using Moody's bond ratings and their associated average historical default and ratings migration probabilities. ${ }^{10}$ Assume that recovery rates are 50 percent of bond principle and accrued interest. For transparency, assume that the individual credit rating yield curves are flat with yields that correspond to those in Table 4. Note that it is the relative level of the credit risk capital requirements generated in this exercise that are of interest, not the absolute levels; the capital estimates are not intended to be comparable to the proposed Basel requirements.

\footnotetext{
${ }^{9}$ The loss severities differ because the bonds have different EYTMs; thus the present value of cash flows is calculated using slightly different rates for each bond.

${ }^{10}$ The average default probabilities are calculated by Moody's over the period 1970-2000. The average ratings migration probabilities are calculated over the 1980-2000 sample period.
} 
HTM credit VaR estimates are calculated as in Table 2. To generate comparable capital estimates, the MTM estimates are calculated by revaluing bonds assuming an instantaneous ratings migration, rather than after a year as is common practice. The term structure of credit yields are unchanged. The HTM and MTM calculations produce discrete loss distributions.

Table 3. Maturity and HTM Tail Losses

\begin{tabular}{lrrrr}
\hline $\begin{array}{l}\text { Year of } \\
\text { Bond } \\
\text { Default }\end{array}$ & $\begin{array}{r}\text { Probability of } \\
\text { Event } \\
\text { (In Percent) }\end{array}$ & $\begin{array}{r}\text { Loss on 20 } \\
\text { year Baa } \\
\text { par Bond }\end{array}$ & $\begin{array}{r}\text { Loss on 10 } \\
\text { year Baa } \\
\text { par Bond }\end{array}$ & $\begin{array}{r}\text { Loss on 5 } \\
\text { year Baa } \\
\text { par Bond }\end{array}$ \\
\hline 1 & .14 & 49.86 & 49.89 & 49.91 \\
2 & .44 & 45.68 & 45.73 & 45.78 \\
3 & .83 & 41.83 & 41.90 & 41.98 \\
4 & 1.34 & 38.28 & 38.37 & 38.47 \\
5 & 1.81 & 35.00 & 35.12 & 35.25 \\
6 & 2.33 & 31.99 & 32.13 & \\
7 & 2.86 & 29.21 & 29.37 & \\
8 & 3.39 & 26.65 & 26.83 & \\
9 & 3.97 & 24.28 & 24.49 & \\
10 & 4.56 & 22.11 & 22.34 & \\
\hline
\end{tabular}

Source: The tail of the HTM cumulative loss distributions for par value Moody's Baa bonds when all bonds have an identical yield to maturity and an identical recovery rate of 50 percent.

Table 4. Hypothetical Bond Yield Curves (In percent)

\begin{tabular}{ccccccc}
\hline Aaa & $\mathrm{Aa}$ & $\mathrm{A}$ & $\mathrm{Baa}$ & $\mathrm{Ba}$ & $\mathrm{B}$ & $\mathrm{Caa}$ \\
\hline 5.8 & 6.6 & 7.6 & 8.8 & 10 & 13 & 15 \\
\hline
\end{tabular}

The Gumbel distribution is used as an interpolating function to fit a continuous distribution for losses that exceed the upper 10 percent threshold for each discrete loss distribution so that capital comparisons can be made at a uniform probability threshold. 
The Gumbel distribution is a member of the extreme value family of limiting probability distributions. ${ }^{11}$ If $X$ represents a loss in the tail of the distribution, and $F(X)$ represents its cumulative probability, the Gumbel cumulative distribution function is given by,

$$
F(X)=1-\exp \left(-\exp \left(-\frac{X-\mu}{\sigma}\right)\right)
$$

The interpolating function is fit by estimating the scaling parameters, $\mu$ and $\sigma$, using nonlinear least squares to minimize the percentage interpolation errors for losses in the upper 10 percent tail of the discrete loss distribution.

The Gumbel scaling parameter estimates and the I percent and 0.5 percent capital estimates for HTM and MTM credit VaR approaches appear in Tables 5 and 6 . Because the 1 percent and 0.5 percent unexpected loss estimates are virtually identical for 5-, 10-, and, 20 -year bonds in the HTM case, only the estimates for the 20-year bond are reported. In contrast, Table 6 shows that the MTM unexpected loss estimates vary substantially according to the maturity of the bond. The maturity-capital relationship for this stylized credit $\mathrm{VaR}$ example is plotted in Figure 1. For the highest quality credits, MTM capital requirements in this example vary between roughly 2 percent and 20 percent of a bond's value depending on the maturity of the issue.

What should one conclude from this comparison? While both of these stylized approaches are crude approximations to what would constitute an operational MTM or HTM credit VaR capital measure for a single credit, the estimates do show striking differences in the recommended capital allocations. In general, HTM credit VaR capital requirements will exceed, and in many cases exceed substantially, one-year MTM capital requirements. Moreover, while maturity is not critically important for individual par bonds under a HTM credit VaR measure, it is critical in the MTM framework.

Some may argue that this comparison has little relevance for the IRB calibration issue, since credit risk measures based upon a single bond have little relationship with the credit risk capital requirements that would be generated in the portfolio setting when diversification effects are formally recognized as they are in the IRB approach. The following section provides evidence that these capital differences are sustained in a portfolio setting.

"See McNeil $(1996,1999)$ for further detail. The Gumbel interpolating function was chosen because it requires only two parameter estimates for calibration and it fits the discrete loss estimates closely. 
Table 5. HTM Capital Estimates

\begin{tabular}{lrrrrrr}
\hline $\begin{array}{l}\text { Moody's } \\
\text { rating }\end{array}$ & $\begin{array}{r}\text { Coupon } \\
\text { (In Percent) }\end{array}$ & $\begin{array}{r}\text { Expected } \\
\text { Return } \\
\text { (In Percent) }\end{array}$ & $\hat{\mu}$ & $\hat{\sigma}$ & $\begin{array}{r}1 \text { Percent } \\
\text { Capital }\end{array}$ & $\begin{array}{r}1 / 2 \text { Percent } \\
\text { Capital }\end{array}$ \\
\hline Aaa & 5.8 & 5.758 & -16.68 & 8.87 & 24.11 & 30.28 \\
Aa & 6.6 & 6.546 & -19.26 & 9.26 & 23.34 & 29.78 \\
A & 7.6 & 7.502 & -18.92 & 9.96 & 26.92 & 33.85 \\
Baa & 8.8 & 8.503 & -18.74 & 12.92 & 40.69 & 49.68 \\
\hline
\end{tabular}

Source: HTM credit risk capital estimates for 20-year bonds sold at par based upon Moody's 1970-2000 average cumulative default probabilities with an assumed 50 percent default recovery rate. The Gumbel distribution mean and standard deviation scaling factor estimates are $\hat{\mu}$ and $\hat{\sigma}$ respectively.

Table 6. MTM Capital Estimates

\begin{tabular}{lcrrrrr}
\hline $\begin{array}{l}\text { Moody's } \\
\text { Rating }\end{array}$ & $\begin{array}{c}\text { Coupon } \\
\text { (In Percent) }\end{array}$ & Maturity & $\hat{\mu}$ & $\hat{\sigma}$ & $\begin{array}{r}1 \text { Percent } \\
\text { Capital }\end{array}$ & $\begin{array}{r}1 / 2 \text { Percent } \\
\text { Capital }\end{array}$ \\
\hline Aaa & 5.8 & 20 & 1.112 & 3.68 & 18.02 & 20.58 \\
Aaa & 5.8 & 10 & -.127 & 2.66 & 12.11 & 13.96 \\
Aaa & 5.8 & 5 & -1.036 & 1.91 & 7.75 & 9.08 \\
Aaa & 5.8 & 1 & -.306 & .46 & 1.81 & 2.13 \\
$\mathrm{Aa}$ & 6.6 & 20 & .491 & 4.06 & 19.17 & 22.00 \\
$\mathrm{Aa}$ & 6.6 & 10 & .613 & 2.66 & 12.87 & 14.73 \\
$\mathrm{Aa}$ & 6.6 & 5 & -.158 & 1.76 & 7.92 & 9.14 \\
$\mathrm{Aa}$ & 6.6 & 1 & -.297 & .487 & 1.95 & 2.28 \\
$\mathrm{~A}$ & 7.6 & 20 & -1.13 & 4.53 & 19.72 & 22.87 \\
$\mathrm{~A}$ & 7.6 & 10 & -4.775 & 4.42 & 15.55 & 18.62 \\
$\mathrm{~A}$ & 7.6 & 5 & .235 & 1.85 & 8.28 & 9.56 \\
$\mathrm{~A}$ & 7.6 & 1 & -1.51 & .87 & 2.48 & 3.08 \\
$\mathrm{Baa}$ & 8.8 & 20 & -14.76 & 9.44 & 28.66 & 35.22 \\
$\mathrm{Baa}$ & 8.8 & 10 & -10.731 & 6.91 & 21.06 & 25.87 \\
$\mathrm{Baa}$ & 8.8 & 5 & -9.068 & 5.15 & 14.61 & 18.19 \\
$\mathrm{Baa}$ & 8.8 & 1 & -3.810 & 1.75 & 4.23 & 5.44 \\
\hline
\end{tabular}

Source: One-year MTM credit risk capital estimates for par bonds based upon the yield curve assumptions of Table 4, Moody's average ratings transition matrix, and a 50 percent recovery rate. The Gumbel distribution mean and standard deviation scaling factor estimates are $\hat{\mu}$ and $\hat{\sigma}$ respectively. 


\section{PoRtFolio EfFects}

It is possible to provide some results that are suggestive as to whether diversification effects will remove the significant differences between HTM and MTM capital requirements in the single credit case without building an elaborate portfolio model.

Consider a portfolio of bonds from a particular rating category. Assume that these bonds have identical ratings, coupons, maturities, EYTMs, LGDs, and initial market prices. To be concrete, assume that each bond has a future probability of default profile that is equal to Moody's historical average default values. ${ }^{12}$ Furthermore, assume that all future bond default events are independent. The independence assumption is used to facilitate the portfolio calculations and comparisons; it overstates diversification benefits and is not intended to be a prescriptive operational assumption.

Recall that in the HTM model, the present value of a bond's cash flow is a deterministic function of its default date. As a portfolio of bonds mature, some of its constituent credits will default. Under the independence assumptions, the number and timing of bond defaults can be modeled as a multinomial process.

Under the multinomial distribution assumption, the expected number of bond defaults in the $i$ th year is given by $N p_{i}$, where $N$ is the number of bonds in the portfolio and $p_{i}$ is the probability that a bond defaults in year $i$. The variance of the number of bond defaults in year $i$ is $N p_{i}\left(1-p_{i}\right)$, and the covariance between the number of bond defaults in year $i$ and year $j$ is given by $-N p_{i} p_{j}$.

Combining the multinomial distribution of bond defaults with the deterministic present value of bond cash flows conditional on a (non)default event, the mean and standard deviation of the portfolio's expected present value of cash flow distribution (or loss distribution) can be calculated as the weighted sum of the random multinomial default process. In a VaR type capital framework, capital is set equal to "unexpected loss" which is typically measured as the difference between the mean and a selected critical value of the distribution; the unexpected loss measure is often expressed as a multiple of the standard deviation of the VaR distribution.

Under the assumption of independence, the multinomial distribution can also be used to model the number firms that migrate to each transition ratings categories in an MTM portfolio calculation. In these calculations, $p_{i}$ represents the probability a bond migrates from its initial rating to rating category $i$.

${ }^{12}$ By default profile, we mean the probability that the bond defaults after one-year, two-years, and so on. 
Table 7 reports portfolio model estimates for alternative bond rating and maturity categories for both the HTM and MTM capital models. The results are based upon Moody's default and ratings transitions data, and the term structure assumptions of Table 4 . The portfolio results are based upon a portfolio of 20 par value bonds. When bond ratings, transitions, and defaults are independent, 20 bonds provide a substantial amount of diversification. ${ }^{13}$

The results in Table 7 demonstrate that the differences between HTM and MTM credit VaR capital allocations are not erased by diversification effects. If capital requirements were set as a fixed multiple of the respective VaR distribution standard deviations, HTM capital requirements are comparable or larger in every portfolio examined. ${ }^{14}$ While the absolute level of these standard deviations is not informative, their comparative magnitudes do provide information.

For lower quality credits, HTM capital requirements are almost double those set under an MTM framework. It is also important to note that as the maturity of the credit lengthens, MTM capital recommendations increase uniformly. The link between maturity and capital is far less pronounced in the HTM case where recognition of the benefits of intermediate coupon payments can actually lead to lower recommended levels of capital as the maturity of a credit increases.

\section{Maturity CORRECTIONS AND THE IRB APPROACH}

The need to account for maturity effects in an MTM capital approach (Figure 1) is problematic to the extent that the foundation IRB approach is calibrated to an MTM credit VaR model assuming a three-year average credit maturity. While the advanced IRB approach will include a maturity adjustment, the foundation approach does not. ${ }^{15}$

\footnotetext{
${ }^{13}$ Increasing the size of the portfolios does not alter the qualitative aspects of the comparison, it merely generates larger diversification benefits. Again, these capital levels are not intended to be prescriptive.

${ }^{14}$ It should also be noted that the MTM numbers are likely inflated by the wide spread and flat term structure assumptions used in the example. These exceptional spreads at the five-year maturity likely explain why the MTM capital exceeds HTM capital for five-year Aaa bonds as these bonds can only fall in value if they migrate.

15 It should also be noted that the magnitude of the maturity adjustment in the IRB approach should depend on the market structure of credit spreads; wider credit spreads should give rise to a much larger maturity adjustment. It does not appear possible to account for both maturity and the structure of credit spreads in the maturity modification factor that is proposed in the advanced IRB approach.
} 
Table 7. Standard Deviation Estimates for Portfolio VaR Distributions

\begin{tabular}{lrr}
\hline & $\begin{array}{r}\text { HTM Distribution Standard } \\
\text { Deviation Measured as a } \\
\text { Percentage of the Portfolio's } \\
\text { Initial Value }\end{array}$ & $\begin{array}{r}\text { MTM Distribution Standard } \\
\text { Deviation Measured as a } \\
\text { Pharacteristics }\end{array}$ \\
\hline 5-year Aaa & .19 & $\begin{array}{r}\text { Percentage of the Portfolio's } \\
\text { Initial Value }\end{array}$ \\
5-year Aa & .43 & .27 \\
5-year A & .53 & .36 \\
5-year Baa & 1.11 & .40 \\
5-year Ba & 2.9 & .69 \\
5-year B & 5.03 & 1.48 \\
10-year Aaa & .56 & 2.88 \\
10-year Aa & .58 & .47 \\
10-year A & .67 & .55 \\
10-year Baa & 1.13 & .64 \\
10-year Ba & 2.52 & .96 \\
10-year B & 4.06 & 1.74 \\
\hline
\end{tabular}

Given the low capital requirements associated with the foundation IRB approach for high quality credits of all maturities, the new Accord would appear to give foundation IRB banks an incentive to specialize in extending high-quality long maturity credit. This incentive is a sharp contrast to the current accord in which banks are encouraged to retain lower quality credits. While these incentives, to the extent that they do encourage IRB banks to concentrate in high quality credits, may make IRB banks safer under the assumption that the IRB capital requirements are sufficiently prudent, it should be recognized that such borrower characteristics are not typical of those associated with the traditional bank intermediation function. From a policy perspective, it is unclear that banks should be given regulatory incentives that encourage them to lend to credits that historically are well-suited for public debt issuance. Aside from such intermediation policy issues, the issues raised by the differences between HTM and MTM capital question whether the concentration of weakly-capitalized long-term high quality credits in foundation IRB banks will serve to increase bank stability. 


\section{Figure 1. One-Year MTM Capital Requirement by Maturity}

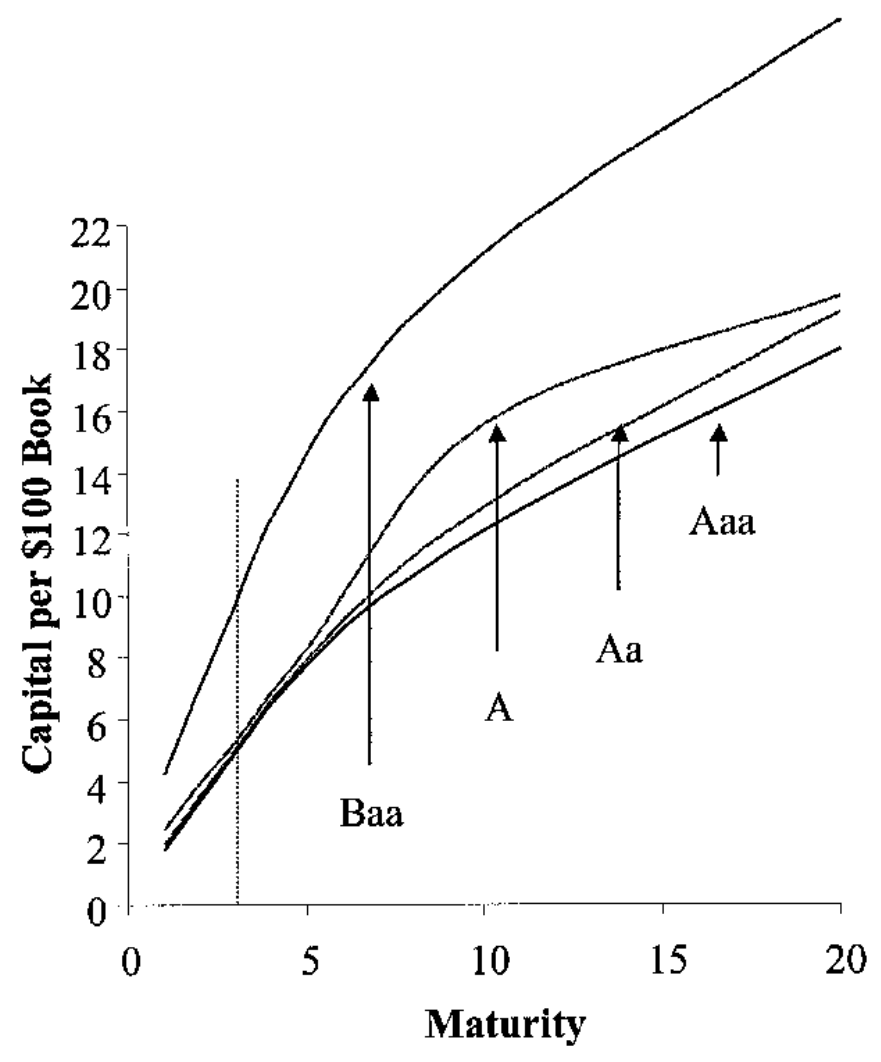

Source: One-year MTM capital charges per $\$ 100$ par value by maturity for alternative Moody's bond rating categorics under the yield curve assumptions of Table 4 . The dashed line is at three-year maturity-the maturity that underlies the calibration of the foundation IRB approach.

\section{ViI. Par Value and the Foundation IRB APPROaCh}

Financial theory suggests that both HTM and MTM credit risk exposure estimates should depend on whether a credit is purchased at a discount or premium. For example, a seasoned credit purchased at a premium has a larger potential LGD than does a par credit. Conversely, seasoned credits purchased at a discount may have smaller LGDs. While it is possible to capture premium/discount effects in an MTM credit risk model, the calibration of the foundation IRB approach does not appear to accommodate these effects.

The foundation IRB approach uses a fixed LGD assumption (50 percent for corporate exposures) that is based upon the historical losses associated with par value corporate credits. The historical loss rates on corporate bonds are typically estimated using the market prices of a defaulted issue shortly after default. Thus, if a bond is purchased at very close to this distress price, its LGD by definition is close to 0 , and yet the foundation IRB approach would assign this 
"junk" bond a punitive capital requirement. The converse is true of credits purchased at a premium: foundation IRB capital requirements do not recognize the larger LGD associated with credits with book values in excess of par.

While the advanced IRB approach has the capacity to solve this issue by letting banks calculate the expected loss given default, few banks are expected to qualify for the advanced IRB level in the near future. An unintended consequence of the foundation IRB calibration is to effectively exclude foundation IRB banks from participating in the market for distressed credits and socalled fallen angels. It should be noted that the existing capital framework does not discourage such participation as all corporate credits receive the same capital treatment.

\section{THE IRB AND LOAN LOSS RESERVES}

The final calibration issue raised in this note concerns the relationship between capital measures and loan loss reserve policies for banking book assets. While a significant ratings downgrade will reduce the market value of a credit, the change in market value need not be reflected in the carrying value of banking book assets. The prudential coverage provided by the stylized HTM credit VaR approach is not sensitive to a bank's loss reserving policy if the loss distribution is calculated relative to true book value of a credit. In contrast, if the general loan loss reserves of a bank are not required to reflect the accumulated change in a credit's market value, a one-year MTM capital framework could leave banks seriously undercapitalized. This is especially true if the IRB approach induces banks to concentrate in high quality long-term credits, as for these issues, credit events are predominately downgrades.

Consider the earlier one-year MTM capital allocation example. A 20-year Moody's Aaa-rated bond purchased at par would require capital of 18.02 under a 1 percent threshold and the yield curve assumptions in Table 4. If the bond were to be downgraded after one-year to Baa, and yields were to remain unchanged, the bond would have a market value of 72.77 . If the MTM credit VaR calculations were performed for a 19-year Baa bond with a coupon rate of 5.8 percent, its 1 percent ten-year MTM capital requirement would be 23.28 . The ratings downgrade would cause a banks capital requirement to rise by 5.26 , from 18.02 to 23.28 . Unless the bank provisions for the MTM loss on the bond, the new capital requirement would, however, not even cover the almost certain loss of 27.23 that would occur if the bond were liquidated.

In the jargon of credit $\mathrm{VaR}$, in this example when yields remain unchanged, the change in the value of the bond that occurs because of the ratings change primarily reflects the expected loss on the bond, whereas the new Baa capital charge of 23.28 represents the bond's updated unexpected loss exposure. Unless loan loss provisions reflect the cumulative change in the market value of a credit since its initiation, the nominal probability threshold used in the one-year MTM credit VaR capital allocation is no longer a measure of the prudential rigor of the capital allocation. 
The issue of provisioning standards is critically important for the IRB approach. Judging by the large capital requirements for lower quality credits in Table 1, the IRB appears to compensate for the lack of a mandated loan loss reserve policy by assuming; (a) that lower quality credits are initially of much higher quality; and (b) by calculating capital requirements using the gross (par value) of banking book credits, rather than an updated MTM value as is normal practice. In other words, it appears as if the IRB capital charge includes both the expected and the unexpected loss from a one-year MTM credit VaR model, assuming that all credits are booked at par value and that all lower quality credits have substantial unexpected loss components.

This IRB calibration-including both expected and unexpected losses in the capital requirement - will have two effects. The first effect relates to the discount or premium issue already discussed: IRB banks will face strong incentives to avoid acquiring discounted credits. This incentive may complicate bank restructurings as healthy banks will be discouraged from purchasing distressed credits. A second potential effect relates to loan loss provisioning incentives. So long as general loan loss provisions count as Tier 2 capital up to a limit of 1.25 percent of total risk-weighted assets, recognizing a general loan loss provision on a downgraded asset will reduce a banks capital adequacy measure.

To the extent that IRB capital for low-rated credits includes an accurate estimate of expected and unexpected losses, any general loan loss provision made by an IRB bank for these credits would over-capitalize these credits. Thus, the incentives for loan loss provisioning will differ according to the banks selection of a capital scheme. Banks operating under the IRB approach face especially strong incentives to avoid provisioning for anticipatory loan losses. Banks operating under the standardized approach will not face these heightened incentives. Unless provision standards are explicitly accounted for in these approaches, the alternative systems proposed under the new Accord will likely encourage significant differences in bank provisioning behavior, further distorting the information content and international comparability of bank loan loss reserve accounts.

\section{Conclusions}

Under the proposed calibration, the new Accord has the potential to create a number of unintended consequences. The capital difference between the standardized and IRB approaches could create incentives that discourage banks from investing in credit risk models and encourage the least capable banks to bear larger credit risks. The capital relief provided by the IRB approach for high quality credits is based on a one-year MTM model assumption that may significantly understate the risks on a HTM credit portfolio. Because the IRB approaches are calibrated for three-year par credits, depending on the maturity or the value of the credit relation to par they include significant incentives to either invest in, or avoid investing in, specific credits. By including expected loss estimates in IRB capital requirements, the IRB approaches will discourage banks from making accurate loan loss provisions and discourage banks from investing in fairly valued distressed credits. 


\section{REFERENCES}

Bank for International Settlements, 1988, International Convergence of Capital Measurement and Capital Standards, Basel Committee on Banking Supervision, Basel.

-_ 1999a, Credit Risk Modeling: Current Practices and Applications, Basel Committee on Banking Supervision, Basel.

—_ 1999b, A New Capital Adequacy Framework, Basel Committee on Banking Supervision, Basel.

—_, 2001, The New Basel Accord, Basel Committee on Banking Supervision, Basel.

Cass, Dwight, Matthew Crabbe, and Carla Schenke, 2001, "Basel Part Two: the Jury's Verdict," Risk, Vol. 14, No. 2.

Kupiec, Paul, 2001, “What Exactly Does Credit VaR Measure?” forthcoming, The Journal of Derivatives.

__ 2001, "Estimating Credit Risk Capital: What's the Use?" The Journal of Risk Finance, Vol. 2, No. 3, (Spring).

McNeil, Alexander, 1996, "Estimating the Tails of Loss Severity Distributions using Extreme Value Theory,” Department Mathematik, ETH Zentrum, Zurich, mcneil@math.ethz.ch

_ 1999, "Extreme Value Theory for Risk Managers," Department Mathematik, ETH Zentrum, Zurich, mcneil@math.ethz.ch

Moody's Investors Service, 2001, "Default and Recovery Rates of Corporate Bond Issuers: 2000," (February).

Saunders, Anthony, Anand Srinivasan, and Ingo Walter, 1998, "Price Formation in the OTC Corporate Bond Markets: A Field Study of the Inter-Dealer Market," New York University Salomon Center, Working Paper S-99-7.

Standard \& Poor's, 2001, "Ratings Performance 2000: Default Transition, Recovery, and Spreads," (January). 